\title{
Penyuluhan: Pemanfaatan Pelayanan Kesehatan yang Optimal pada Penyakit Langka
}

\author{
Dyah Ayu Sulistyaning Cipta ${ }^{1}$, Trio Ageng Prayitno ${ }^{2}$, Era Dewi Kartika ${ }^{3}$ \\ ${ }^{123)}$ IKIP Budi Utomo, Malang, Jawa Timur, Indonesia \\ ${ }^{1 *}$ Email: dyahayu.esce@gmail.com \\ ${ }^{2}$ Email: trioageng@gmail.com \\ ${ }^{3}$ Email: erfolgera@gmail.com
}

\begin{abstract}
The purpose of holding counseling in the form of a talkshow with the theme Role of Families in Bridging the Affect of Rare Disease with Optimal Health Services is to increase public awareness of children with special needs, especially rare diseases, and foster parents' enthusiasm in bridging children with rare diseases with optimal health services Thus, it is expected that children with special needs will get support both physically and psychologically, so that they can develop their own potential, grow to become empowered individuals, and get the best quality of life. This event is also a form of our support for parents with children with special needs, especially with rare diseases. This ceremony was held at the 6th Floor Hall of RSI Aisyiyah Malang on Saturday, March 2, 2019.
\end{abstract}

Keyword: rare disease, optimal health services, special needs

\section{PENDAHULUAN}

Indonesia Care for Rare Diseases adalah sebuah komunitas yang mewadahi para keluarga penyintas penyakit langka. Penyakit langka dalam http://www.raredisease.org.uk/what-is-a-raredisease/ disebutkan bahwa, "A rare disease is defined by the European Union as one that affects less than 5 in 10,000 of the general population. Merujuk pada definisi tersebut, untuk mengkategorikan suatu penyakit atau kelainan langka jika angka kejadiannya ditemukan 1 : 2000 atau lebih.

Dari sebanyak 6000 jenis penyakit langka, hingga saat ini hanya 5\% saja yang pengobatannya telah disetujui oleh Food and Drug Administrasion (Indonesia Care for Rare Diseases, 2017). Kebanyakan Rare Diseases bersifat menetap dan akan terus disandang seumur hidup. Tetapi ada pula yang dapat catch up dengan sendirinya seiring bertambahnya usia, atau ada pula yang harus diatasi dengan surgery dan obatobatan. Penyakit langka menjadi penyebab kematian anak usia kurang dari 1 tahun. Selain itu, tak jarang juga penyakit langka menyebabkan disabilitas atau anak berkebutuhan khusus (ABK).

Apapun kondisinya, sejatinya setiap anak memiliki hak yang sama, termasuk ABK. Namun hadirnya ABK, khususnya dengan penyakit langka, terkadang masih sulit untuk bisa diterima, bahkan oleh orang tua atau keluarganya sendiri. Padahal, menujrut Faradina (2016: 395), "Keluarga diharapkan dapat lebih memberikan dukungan dan perhatian pada orang tua yang memiliki anak berkebutuhan khusus sehingga orang tua dapat memberikan pengasuhan yang baik pada anak."

Proses penerimaan ABK memang
bukan hal yang mudah karena problematikanya melingkupi banyak aspek, salah satunya adalah masih adanya persepsi negatif terhadap $\mathrm{ABK}$, yang membuat orang tua merasa malu atau bahkan putus asa dengan kondisi sang anak. ABK juga ingin diperhatikan, ingin dipuji, ingin disapa dengan baik, dan diperlakukan dengan elusan atau kemanjaan dari orang sekitar anak (Anggraini, 2013: 264). Jadi, penerimaan orang tua adalah kunci awal agar sang anak dapat tumbuh menjadi pribadi yang percaya 
diri dan berdaya. Oleh karena itu, dukungan sosial sangatlah diperlukan agar ABK dapat tumbuh dan berkembang dengan optimal.

ABK, khususnya dengan penyakit langka, tentu juga membutuhkan pelayanan kesehatan yang baik agar mendapatkan perawatan yang optimal, sehingga $A B K$ dapat tumbuh sehat dan mampu mengembangkan potensi diri dengan lebih baik. Anak berkebutuhan khusus, terutama dengan penyakit langka, sangat membutuhkan dukungan secara fisik maupun mental untuk dapat mencapai tumbuh kembang yang optimal dan mendapatkan kualitas hidup yang baik.

Sama halnya seperti yang disebutkan oleh Huyard (2012), "Rare disease organizations are issue-based (people gather to struggle with common problems that they want to solve together) while coalitions of such organizations tend to be rarity-based (organisations come together because their members address rare disorders)" maka penulis bersama komunitas Indonesia Care for Rare Diseaeses - sebagai mitramemberikan bentuk dukungan terhadap anak-anak istimewa tersebut dengan mengadakan penyuluhan berupa talkshow bertajuk "Peran Keluarga dalam Menjembatani Penyitas Penyakit Langka dengan Pelayanan Kesehatan yang Optimal.”

\section{METODE PELAKSANAAN}

Penyuluhan dilakukan di Auala lantai 6 RSI Aisyiyah Malang pada hari Sabtu, tanggal 2 Maret 2019. Penulis yang bertindak sebagai volunteer membantu pelaksanaan penyuluhan dari persiapan hingga terselesaikannya acara. Berikut adalah diagram alir langkah-langkah yang dilakukan penulis dalam pelaksanaan pengabdian kepada masyarakat ini,

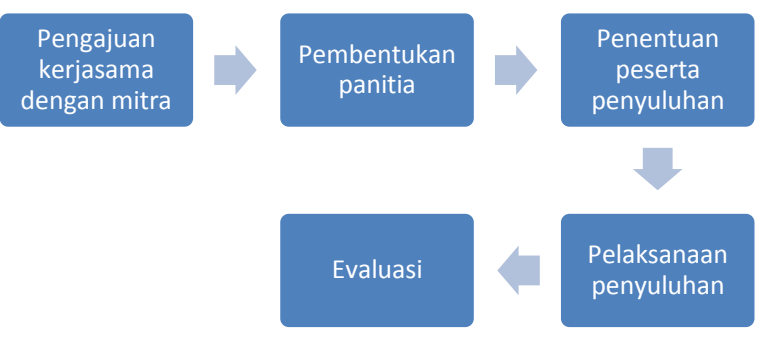

Mitra dalam kegiatan pengabdian masyarakat ini adalah Indonesia Care for Rare Diseases wilayah Malang. Penulis mengajukan diri sebagai volunteer yang akan mewujudkan kegiatan penyuluhan dalam rangka peringatan Rare Diseases Day 2019. Selanjutnya dilakukan pembentukan panitia yang bertanggung jawab dalam seluruh rangkaian penuluhan. Peserta yang boleh terlibat dalam penyuluhan adalah para keluarga penyintas rare diseases. Karena beberapa kode etik yang perlu dijaga, maka penyuluhan ini tidak terbuka untuk umum. Pelaksanaan penyuluhan melibatkan beberapa dokter, psikolog, hingga terapis ABK. Evaluasi dilakukan beberapa hari setelah kegiatan. Tujuan evaluasi ini, selain untuk pertanggung jawaban dana yang digunakan, juga untuk melihat keberhasilan dan efektivitas pelaksanaan penyuluhan.

Foto kegiatan dalam rapat koordinasi panitia sebelum pelaksanaan penyuluhan dapat dilihat pada Gambar 1. 


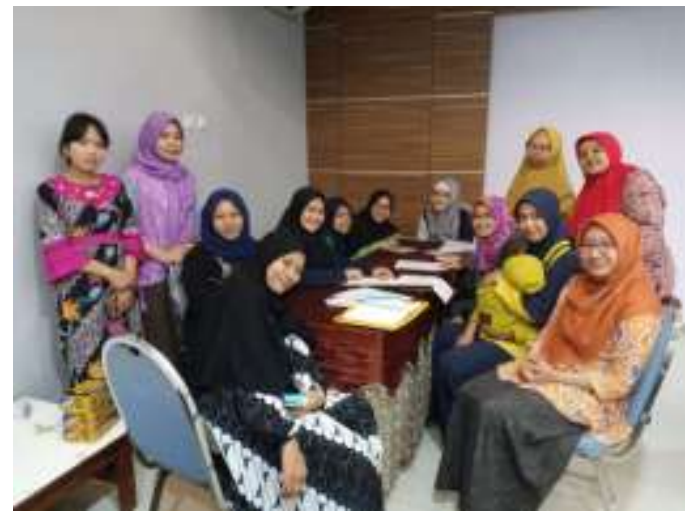

\section{Gambar 1. Foto Kegiatan Rapat Koordinasi Panitia}

\section{HASIL DAN PEMBAHASAN}

\section{A. Hasil Pengabdian Kepada Masyarakat}

Sebagai suguhan pembuka, acara yang dihadiri oleh 100 peserta ini menampilkan anak-anak berkebutuhan khusus dari Children Creativity for Tomorrrow (CRAFT) dengan pertunjukan angklungnya. Lagu balonku dimainkan dengan sangat antusias oleh anak-anak istimewa berbaju putih.
Penyuluhan yang dikemas dalam acara talkshow dalam menyambut Rare Diseases Day (Hari Penyakit langka sedunia) ini dibuka oleh Ketua Ikatan Dokter Anak Indonesia (IDAI) Malang, dr. Haryudi Adi Cahyono, Sp.A (K), konsultan tumbuh kembang anak yang didokumentasikan dalam gambar 2 berikut ini.

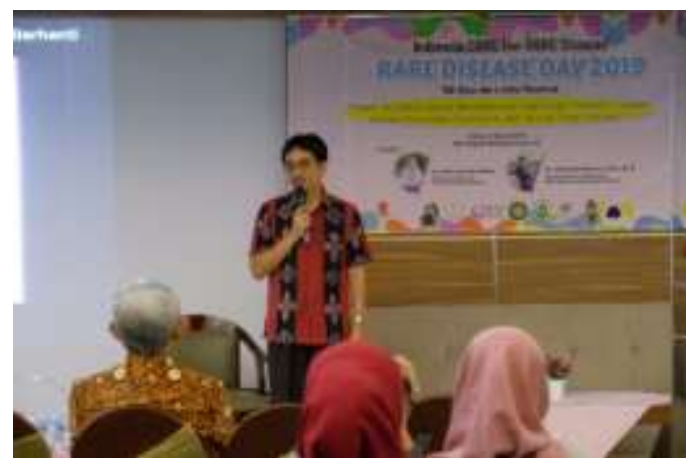

\section{Gambar 2. Foto Kegiatan dr. Haryudi A.C., Sp.A (K) Membuka Acara}

Tujuan utama digelarnya acara dengan Master of Ceremony (MC) dr. Linda Oktaviana Suci Cyntia ini adalah untuk membangun awarenes masyarakat terhadap penyakit langka sekaligus untuk merangkul keluarga para penyintas penyakit langka agar dapat berjuang untuk mencapai kualitas hidup yang optimal. "Dengan perawatan medis dan psikologis yang tepat dan sesuai, maka akan memperbaiki kualitas kehidupan dan memperpanjang harapan hidup bagi penyintas penyakit langka," ucap dr. Ariani, Sp.A (K) saat memaparkan materi dalam penyuluhan yang didokumentasikan dalam gambar 3 berikut ini. 


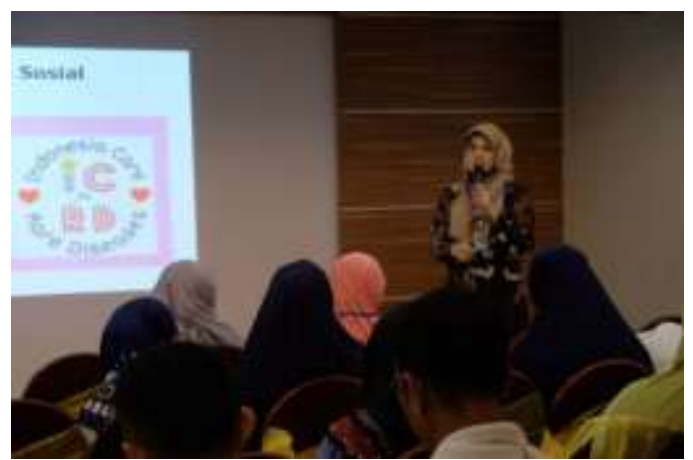

Gambar 3. Foto Kegiatan Pemaparan Materi dari dr. Ariani, Sp.A (K)

Cara mengenali ciri anak dengan penyakit langka, diantaranya adalah sesak napas seegera setelah lahir, biru, sulit minum, diare kronis, dehidrasi, gagal tumbuh kembang, pembengkakan organ tubuh, nyeri tulang, mudah lelah, pendarahan, dan memar. Gejala lainnya adalah kegagalan dari perkembangan beberapa organ tubuh, bentuk wajah yang khas, dan ketidaknormalan pada kerangka tubuh. Jangan Ragu Konsultasi dengan dokter jika ada kecurigaan.

Permasalahan-permasalahan yang didapati oleh penyintas penyakit langka diantaranya adalah populasi yang teramat sedikit sehingga mengakibatkan sulitnya pengetahuan dan informasi yang didapatkan terkait penyakit langka ini. Stigmatisasi dari masyarakat yang mengucilkan penyintas penyakit langa semakin memperkeruh keadaan sehingga penyintas penyakit langka kurang melakukan interaksi sosial. Lalu didukung pula oleh isolasi pendidikan, penyintas penyakit langka sering kali dihadapkan pada penolakan lembaga pendidikan (Cipta, 2017: 159).

Tidak hanya itu, keterbatasan dalam regulasi dan ketersediaan obat juga dialami oleh penyakit langka. Kalau perusahaan farmasi hanya memperhitungkan profit, tentu saja tidak akan ada yang mau menjual obat- obatan untuk penyakit langka ini (Cipta, 2019: 14).

. Beberapa manajemen terapi yang bisa dilakukan terhadap penyintas penyakit langka, diantaranya adalah (1) Dengan perawatan medis dan psikologis yang tepat dan sesuai, akan memperbaiki kualitas kehidupan dan memperpanjang harapan hidup, (2) Diharapkan pemerintah dapat mendukung anak-anak dengan penyakit langka, begitu juga orangtua dan keluarga dalam menghadapi tantangan penyakit langka untuk mendapatkan akses setara ke layanan kesehatan dan kehidupan berkualitas, (3) Manajemen komprehensif holistik interdisipliner, (3) Pemberdayaan komunitas dan masyarakat, (4) Ciptakan peluang jaringan secara global, dorong kemitraan.

Salah satu hal terberat yang dialami oleh penyintas penyakit langka adalah adanya kerusakan jantung yang disebut dengan Penyakit Jantung Bawaan (PJB). dalam penyuluhan ini, juga mendatangkan konsultan jantung anak, dr. Dyahris Koentartiwi, Sp.A (K) yang memaparkan bagaimana deteksi dini terhadap adanya penyakit jantung bawaan. Selain adanya sesak napas, PJB juga ditandai dengan warna biru pada wajah, kuku, telapak tangan, dan kaki. Pemaparan didokumentasikan pada gambar 4 berikut. 


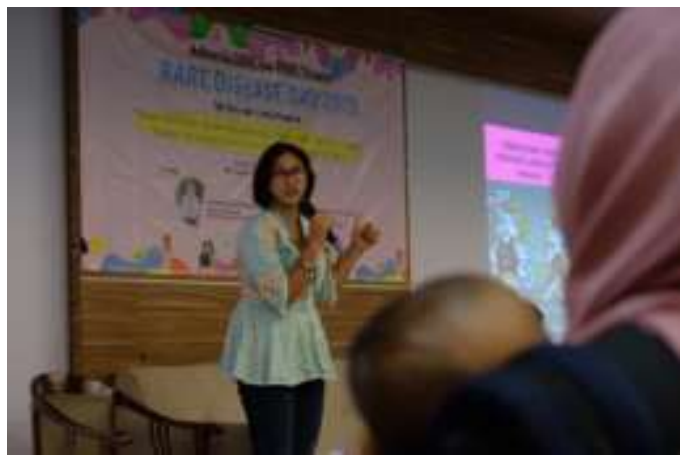

\section{Gambar 4. Foto Kegiatan Pemaparan Materi dari dr. Dyahris K., Sp.A (K)}

Tidak hanya mengulas materi, talkshow gratis ini juga menyisihkan waktu untuk para orang tua dengan anak rare diseases agar mengisahkan bagaimana perjuangan mereka dalam merawat anak rare-nya. Sejenak haru menyelimuti seluruh ruangan saat beberapa panitia mengisahkan tentang perjuangan putra putri rare-nya.

Beberapa penyintas rare diseases yang hadir dalam penyuluhan adalah: Gambar 5, seorang penyintas additional chromosome 8. Belum ada namanya untuk penyakit ini. Penyintas trisomi 8 ditandai dengan masalah penyakit jangtung bawaan (PJB) yang berat hingga memerlukan operasi besar, Agenesis Corpus Callosum yaitu tidak memiliki otak tengah, juga microcephaly. Kondisi ini menjadikan penyintasnya mengalami intellectual disability yang bisa saja akan terus bergantung kepada kursi roda. Mungkin salah satu kendala bagi dunia medis dalam melakukan penelitian bagi penyakit langka adalah umur yang tidak panjang. Sejatinya hanya Tuhan yang memberi umur, namuan penyintas penyakit langka umumnya meninggal sebelum ulang tahunnya yang ke5, bahkan beberapa penyakit langka tidak bertahan hingga usia 1 tahun..

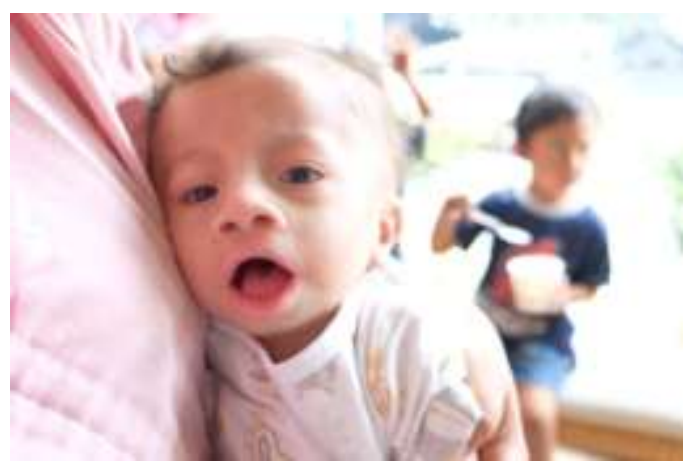

Gambar 5. Foto Kegiatan: Penyintas Penyakit Langka: Additional Chromosome 8

Gambar 6 adalah penyintas Pierre Robin Squence (PRS) non isolated. Kondisi ini ditandai dengan micrognathia atau dagu yang terlalu kecil, retrognathia atau rahang bawah terlalu mundur, high-arched palate atau langit-langit mulut yang tinggi. Keadaan ini menjadikan ia baru bisa makan dan minum dengan mulutnya di usia dua tahun. Sebelumnya ia menggunakan nasogastric tube (NGT), yaitu selang yang dimasukkan melalui hidung hingga ke lambungnya. Struktur rahangnya tidak normal. Lidahnya mudah turun dan sewaktu-waktu bisa menutup jalan napas. Ia hanya boleh diposisikan miring atau tengkurap saat tidur. Nyawanya bisa terancam jika ia sampai tidur telentang. Selain PRS, ia juga microcephaly sehingga perkembangannya terhambat. Ada syndrome tertentu ia miliki, entah apa. 
Keterbatasan biaya menjadi penghalang untuk melanjutkan penemuan diagnosanya.

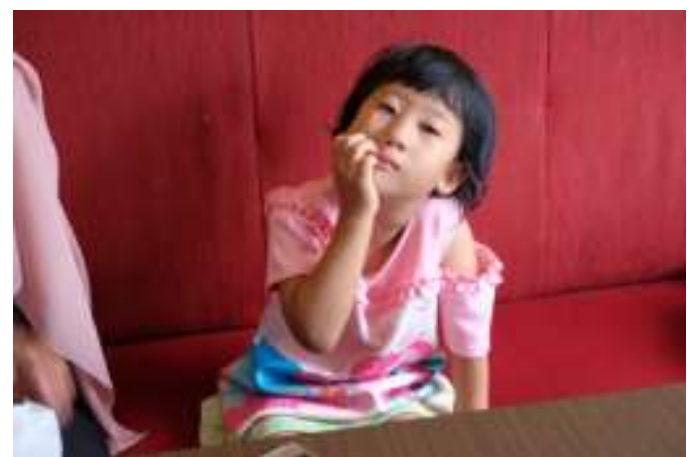

\section{Gambar 6. Foto Kegiatan: Penyintas Penyakit Langka: PRS Non Isolated}

Kegiatan penyuluhan yang dikemas dalam talkshow bertajuk Peran Keluarga dalam Menjembatani Penyitas Penyakit Langka dengan Pelayanan Kesehatan yang Optimal ini dihadiri oleh 100 peserta yang berlatar belakang keluarga penyintas rare diseases, para tenaga medis, terapis, psikolog, dan penggiat disabilitas. Semarak dan riushnya peserta dalam mengikuti talkshow dapat dilihat pada gambar 7 berikut.

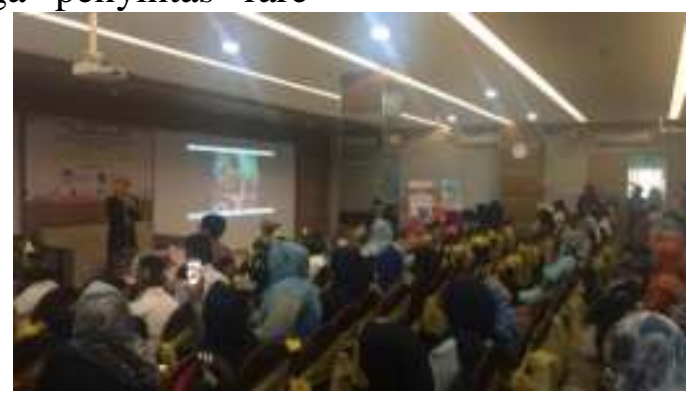

Gambar 7. Foto Kegiatan: Peserta Penyuluhan

\section{B. Pembahasan}

Kegiatan pengabdian kepada masyarakat ini berupa penyuluhan yang dikemas dalam talkshow. Acara ini ditujukan untuk merangkul orang tua dengan anak penyintas penyakit langka. Dengan permasalahan yang kompleks yang dialami oleh para penyintas penyakit langka dan keluarganya, maka kegiatan penyuluhan ini akan mendampingi keluarga penyintas kelainan langka untuk dapat memperoleh pelayanan kesehatan yang optimal.

Seperti yang dituturkan oleh Iskandar (2016: 786), semakin tingginya tuntutan masyarakat akan kualitas pelayanan dan fasilitas kesehatan yang efektif dan efisien, mau tidak mau memacu rumah sakit agar berupaya memenuhi tuntutan-tuntutan tersebut. Maka dalam hal ini, untuk meningkatkan pelayanan yang optimal, tidak ada salahnya jika para keluarga penyintas penyakit langka proaktif terhadap pihak rumah sakit, meminta kejelasan dan bertanya secara detail mengenai kondisinya, serta juga rujukan untuk penanganan yang optimal.

Orang tua diharapkan tahu secara detail mengenai kondisi anaknya, serta dapat mendiskusikan dengan dokter untuk dapat memperoleh penanganan yang optimal. Sangat disayangkan jika ada orang tua penyingtas penyakit langka yang kurang memahami kondisi anaknya sehingga ia hanya bisa pasrah terhadap kondisi anak tanpa mengupayakan apapun.

Sejalan dengan hal tersebut, Ostergaard (2014) memaparkan, "The vast majority of 
rare diseases affect more than one organ of the body, and eighty-five percent of the patients have symptoms within the initial five years of life." Maka di sini, diharapkan orang tua dapat mengoptimalkan pemeriksaan terhadap anak agar dapat dilakukan secara mendetail. Orang tua harus memahami bahwa penyakit langka hampir selalu diiringi dengan penyakit penyerta lainnya. Perlu dilakukan pemeriksaan lanjutan terhadap fungsi jantung, hati, ginjal, telinga, mata, maupun organ lain sesuai dengan syndrome yang dimiliki anak.

Penanganan yang tepat bagi penyakit langka memungkinkan penyintas penyakit langka dapat meningkatkan optimalisasi hidup mereka. Hal ini sejalan dengan yang disebutkan Tambuyzer (2014) menyebutkan, "The right therapy for the right patient at the right time is the most important approach for the provision of proper health care". Tidak hanya tentang umur yang panjang, optimalisasi ini juga berkaitan dengan kualitas hidup mereka. Penting sekali diupayakan agar penyintas penyakit langka kelak dapat hidup secara mandiri dan tidak bergantung kepada siapapun. Dalam hal ini, penyintas penyakit langka perlu melakukan terapi seperti yang dijelaskan pada bab hasil penelitian.

Untuk saat ini, China merupakan salah satu negara yang sedang mengadakan penelitian untuk memperbaiki pelayanan kesehatan bagi penyakit langka (Cui, dkk: 2014). Harapannya, berikutnya Indonesiapun akan melakukan hal yang sama untuk memperbaiki layanan kesehatan bagi penyakit langka. Penyintas penyakit langka tidak lagi dihadapkan pada penolakan dari berbagai layanan kesehatan, sosial, maupun pendidikan. Sebailknya, penyintas penyakit langka berharap akan mendapatkan aksesibilitas dan layanan kesehatan, sosial, maupun pendidikan yang memadai.

Pentingnya kegiatan talkshow ini, selain sebagai rujukan para orang tua agar dapat memanfaatkan pelayanan kesehatan yang optimal adalah juga untuk membuka wawasan bagi para orang tua agar dapat membuka diri, bahwa anak rare-nya dapat hidup mandiri. Hal ini sejalan dengan penelitian Pogany (2014) yang mempersiapkan orang dewasa muda (dan keluarga mereka) hidup dengan beberapa jenis penyakit langka dan cacat hingga mereka miliki kehidupan dan pekerjaan mandiri yang layak.

Orang tua perlu membuka diri dengan melihat dunia bahwa sudah ada beberapa contoh penyintas penyakit langka yang mampu hidup mandiri dan berkarya dengan sangat luar biasa. Sebagai contoh, salah satu penyintas Retinopathyof Prematurity (ROP) dalam Komunitas Indonesia Care for Rare Diseaes yang berhasil menjadi muskius berbakat. Tidak hanhya dengan suara yang memukau, ia juga pandai bermain piano, bahkan penyanyi ini tampil di Opening Ceremony Asian Para Games.

Dengan menitik beratkan pada Wilson (2017) yang melakukan lokakarya berupa presentasi dari dan partisipasi oleh para pakar di Industri, Administrasi Makanan dan Obatobatan, dan akademisi yang berfokus pada contoh-contoh studi kasus tentang mekanisme yang berhasil bagi mereka yang ingin memberikan akses awal ke terapi eksperimental untuk pasien, maka penulis bersama Komunitas Indonesia Care for Rare Diseases menggelar penyuluhan yang dibalut dalam acara talkshow ini.

\section{KESIMPULAN}

Kegiatan ini dapat meningkatkan kepedulian masyarakat terhadap ABK, khususnya penyakit langka, serta menumbuhkan semangat orang tua dalam menjembatani anak dengan penyakit langka dengan pelayanan kesehatan yang optimal. Dengan demikian, diharapkan para penyintas penyakit langka mendapatkan dukungan secara fisik maupun psikis, agar mereka dapat mengembangkan potensi diri, tumbuh 
menjadi pribadi yang berdaya, dan mendapatkan kualitas hidup terbaik.

\section{REFERENSI}

Anggraini, Rima Rizki. 2013. Persepsi Orang Tua terhadap Anak Berkebutuhan Khusus. E-Jupekhu. 1 (1): 258 - 265

Cipta, Dyah Ayu Sulistyaning. 2017. Analisis Persepsi dan Harapan Orang Tua Penyintas Rare Disesaes terhadap Pendidikan Inklusi di Indonesia. Artikel disajikan dalam Prosiding: Praktik Pendidikan Bagi Penyandang Disabilitas. Oleh PSLD Universitas Brawijaya, Desember 2017.

Cipta, Dyah Ayu Sulistyaning. 2019. Malang Post - Tunjukkan Pedulimu pada Penyakit Langka. Opini, 4 Maret 2019, pp. 14

Cui, Yazhou, dkk. 2014. China Launched a Pilot Project to Improve its Rare Disease Healthcare Levels. Orphanet Journal of Rare Diseases. 9: 14

Faradina, Novira. 2016. Penerimaan Diri pada Orang Tua yang Memiliki Anak Berkebutuhan Khusus. eJournal Psikologi. 4 (4): 386 - 396

Genetic Alliance UK. 2016. "What is Rare Disease", (online), (http://www.raredisease.org.uk/whatis-a-rare-disease/, diakses 1 Maret 2019)

Huyard, Caroline. 2012. The Emergence of the Cause of Rare Diseases and Rare Disease Patients' Movement. Orphanet Journal of Rare Diseases. 7 (Suppl 2): A34.

Indonesia Care for Rare Diseases. 2017. "Rare Diseases", (online), (https://m.facebook.com/profile.php?id $=1732995363678518 \&$ ref $=$ content_filt er, diakses 1 Maret 2019)

Iskandar, Soleh. 2016. Pelayanan Kesehatan dalam Meningkatkan Kepuasan Masyarakat di Rumah Sakit Panglima Sebaya Kabupaten Paser. 2016. eJournal Ilmu Pemerintahan. 4 (2): 777-788

Ostergaard, John R. 2014. Perspective having a Centre of Expertise that covers more than one rare disease. Orphanet Journal of Rare Diseases. 9 (Suppl 1): $\mathrm{O} 2$

Pogany, Gabor. 2014. Can People Living with a Rare Disease be Independent? Inspiring Personal Stories. Orphanet Journal of Rare Diseases. 9 (Suppl 1): O34.

Tambuyzer, Erik T., dkk. 2014. The Biopontis Alliance Rare Disease Foundation (BARDF) - an innovative model for early stage rare disease therapy financing and development. Orphanet Journal of Rare Diseases. 9 (Suppl 1): O18

Wilson, Bryan A. 2017. 8th Annual Rare Disease Scientific Workshop: Evaluating Early Access Models for Patients: Flashpoints, Frameworks \& Case Studies for Advancement: A Summary. Rare Diseases Journal. 2 (2): $6-17$ 